\title{
Assessing Nitrogen Treatment Efficiency in Schima Superba Seedlings Detected Using Hyperspectral Reflectance
}

\author{
Miaomiao Cheng ${ }^{1}$, Hong Jiang ${ }^{1,2, *}$, Zheng Guo ${ }^{3}$, and Xiuying Zhang ${ }^{1}$ \\ ${ }^{1}$ International Institute for Earth System Science, Nanjing University, Nanjing, China \\ ${ }^{2}$ Zhejiang Provincial Key Laboratory of Carbon Cycling in Forest Ecosystems and Carbon Sequestration, Zhejiang Agriculture \\ and Forestry University, Hangzhou, Zhejiang, Hangzhou, China \\ ${ }^{3}$ National Satellite Meteorological Center, Beijing, China
}

Received 29 March 2013, accepted 27 November 2013

\begin{abstract}
The sharp change in nitrate $(\mathrm{N})$ deposition fluxes due to anthropogenic influences has major consequences for terrestrial plant productivity. Early detection of plants under nitrate stress is important for forest management in the subtropical region. This study used leaf-scale hyperspectral reflectance measurements to detect the seedling growth response of Schima superba (S. superba) under simulated N deposition during a period of two years. Two-year-old S. superba seedlings were planted under natural field conditions and treated with four $\mathrm{N}$ treatments at CK, LN-6, MN-10, and HN-24g N m${ }^{-2}$ year ${ }^{-1}$. The chlorophyll content and leaf reflectance were examined to detect the N addition temporal effects. Results indicated that $S$. superba responded significantly with differences in chlorophyll content and leaf reflectance to $\mathrm{N}$ additional treatment. Compared with the $\mathrm{N}$ deficiency $(\mathrm{CK})$ plots, plots with higher $\mathrm{N}$ addition rate $(\mathrm{HN})$ reduced the chlorophyll concentration of $S$. superba seedlings. However, the long-term observed impact of LN and MN treatments increased the S. superba chlorophyll during the two years. Nitrogen additional treatments can be distinguished using the hyperspectral indices $\left(R_{700} / R_{720}, R_{695} / R_{420}\right.$, and $\left.R_{695} / R_{760}\right)$ retrieved from the differences in leaf reflectance at the green spectrum and the red spectrum. The derivative shift to longer wavelength peaks with increasing $\mathrm{N}$ supply, accompanied by the increase in chlorophyll content. Leaf reflectance at $559 \mathrm{~nm}$ was negatively correlated with leaf chlorophyll content $(\mathrm{R}=-0.77)$. The identified $\mathrm{N}$ specific spectral ratios may be used for image interpretation and plant $\mathrm{N}$ status diagnosis for site-specific $\mathrm{N}$ management.
\end{abstract}

Key words: Nitrogen deposition, Stress detection, Hyperspectral reflectance, Chlorophyll content, Subtropical species

Citation: Cheng, M., H. Jiang, Z. Guo, and X. Zhang, 2014: Assessing nitrogen treatment efficiency in Schima superba seedlings detected using hyperspectral reflectance. Terr. Atmos. Ocean. Sci., 25, 369-380, doi: 10.3319/TAO.2013.11.27.01(A)

\section{INTRODUCTION}

The increase in atmospheric nitrogen oxides (NOx) due to human activities such as fossil fuel use, increasing number of vehicles, fertilization and biomass burning (Richter et al. 2005) has contributed to the perturbation of terrestrial and marine ecosystems, most agricultural and managed-forestry ecosystems (Vitousek et al. 1997; Galloway and Cowling 2002; Bates and Peters 2007). The sharp change in nitrate deposition fluxes due to anthropogenic influences has major consequences for terrestrial and marine productivity and carbon cycling (Galloway et al. 1994; Moffat 1998; van Breemen 2002; Fang and Mu 2007). For-

\footnotetext{
* Corresponding author

E-mail: jianghong_china@hotmail.com
}

est ecosystems have been shown to vary in their responses to increased $\mathrm{N}$ deposition. It could increase primary productivity, biomass accumulation substantially and the fund of soil organic carbon by nitrogen deposition, at least in the short-term in the ecosystems with less nutrition (Vitousek and Howarth 1991). However, it also generally reduces the biological diversity of affected ecosystems with nitrogen saturation and changes the rates and pathways of $\mathrm{N}$ cycling and loss in forest ecosystems (Nixon 1995). Results from $\mathrm{N}$ addition experiments at the Harvard Forest showed that long-term $\mathrm{N}$ addition decreased net primary production and increased tree mortality (Magill et al. 2004). In a seedling experiment on two temperate conifer tree species, Nakaji et al. $(2001,2002)$ found that net photosynthetic rate and biomass production of $C$. japonica seedlings were increased by 
$\mathrm{N}$ addition, while those of $P$. densiflora seedlings were significantly reduced by the highest $\mathrm{N}$ addition. In China most studies on the consequences of enhanced $\mathrm{N}$ deposition were performed on representative broadleaf tree species in the tropical forests of southern China. Results from $\mathrm{N}$ addition experiments in mature forest ecosystems in the Dinghushan Biosphere Reserve (DHSBR) showed that long-term high $\mathrm{N}$ addition exhibited the negative response to $\mathrm{N}$ additions in litter decomposition (Mo et al. 2006). This negative response became stronger with experimental time (Fang and $\mathrm{Mu}$ 2007). In addition, their studies in the DHSBR also indicated that tropical tree species seedling growth response to atmospheric $\mathrm{N}$ deposition may vary depending on rate of $\mathrm{N}$ deposition and species-N-requirement (Mo et al. 2008). However, little information is available about the mid-subtropical forest ecosystem response to the supply of biologically available nitrogen, rapidly increased by industry and agriculture (Mo et al. 2008) and dramatically increased atmospheric $\mathrm{N}$ deposition (Cheng et al. 2013).

Researchers have tried to assess the ecophysiological status of subtropical trees over their growing season to reveal the tree response to $\mathrm{N}$ addition vegetation photosynthesis (Mo et al. 2008), soil respiration (Mo et al. 2007) and vegetation growth parameters ( $\mathrm{Lu}$ et al. 2010, 2011). However, these methods based on the site experiments provide little insight into spatial variability such as regional or large scale forest ecosystems. Determining the spatial distribution is the first step towards localized management practices intended to reveal the effect of increased $\mathrm{N}$ for subtropical trees. Hyperspectral reflectance, a technique used in remote sensing, has potential for detecting the ecophysiological spatial distribution status of trees in the field (Strachan et al. 2002). Hyperspectral reflectance involves the measurement of vegetation reflectance spectra in narrow wavebands $(2 \mathrm{~nm})$ which allows the isolation of reflectance at wavelengths corresponding to individual plant pigments or structural features (Pattey et al. 2001). Carter (1993) reported that there is a significant difference between the reflectance of stressed and non-stressed leaves and generally occurred in the $535-640$ and $685-700 \mathrm{~nm}$ ranges by 8 stress agents among 6 plant species (Carter 1993). A number of indices have been developed to exploit the narrow waveband properties of hyperspectral reflectance spectra. The red edge describes the maximum slope position of reflectance and defines the transition between the red and near infrared spectrum portions (Horler et al. 1983). Reflectance in the red portion is low because of chlorophyll absorption and is high in the near-infrared reflectance (NIR) because of leaf scattering. Thus, the red edge combines two mechanisms by which plant stress due to the variations in chlorophyll content associated with nutrient levels may be indicated. Stress has been shown to cause a shift in the red edge position to shorter wavelengths (Hoque and Hutzler 1992). Several studies have shown that the derivative analysis of the red edge reflectance was actually composed of two or more peak features. The first at around $700 \mathrm{~nm}$ was attributed to the chlorophyll content in the plant leaves and the second at around $725 \mathrm{~nm}$ was attributed to cellular scattering in the leaf (Horler et al. 1983). Hansen and Schjoerring (2003) also indicated that a nitrogen supply to winter wheat caused on average lower reflectance in the visible spectral range (438 - $690 \mathrm{~nm}$ ), while the reflectance was higher in the near infrared spectral range $(750-883 \mathrm{~nm})$.

The increase in population has increased the number of vehicles and energy consumption in the Yangtze River Delta, located in the biggest subtropical forest ecosystem. $\mathrm{N}$ deposition has increased dramatically and has had an effect on the subtropical forest. In Asia the use and emission of reactive $\mathrm{N}$ has increased from $14 \mathrm{Tg} \mathrm{N}$ year-1 in 1961 to $68 \mathrm{Tg} \mathrm{N}_{\text {year }}{ }^{-1}$ in 2000 and is expected to reach $105 \mathrm{Tg} \mathrm{N}_{\text {year-1 }}{ }^{-1}$ in 2030 (Zheng et al. 2002). This has led to high atmospheric $\mathrm{N}$ deposition with $7.12 \mathrm{~kg} \mathrm{~N}^{-1}$ year $^{-1}$ in $1995,32.01 \mathrm{~kg} \mathrm{~N}^{-1} \mathrm{year}^{-1}$ in 2002 (Deng et al. 2007) and $30.9 \mathrm{~kg} \mathrm{~N} \mathrm{ha}^{-1}$ year $^{-1}$ in 2005 (Xie et al. 2008) in the Hangzhou region of China. The objective of this paper is to detect the nitrogen application rate effects (promotion or stress) on subtropical forest trees [Schima superba (S. superba)] using hyperspectral reflectance analysis and indices available in the literature. These results will serve as exploration work in support of subsequent forest management work in conjunction with aircraftbased hyperspectral measurements at this field site.

\section{MATERIALS AND METHODS}

\subsection{Site Description and Experimental Material}

The experiment was conducted on a $100 \mathrm{~m}^{2}$ experimental field located at the Zhejiang A \& F University (ZAFU) near Hangzhou city, China $\left(119^{\circ} 52^{\prime} \mathrm{E}, 30^{\circ} 23^{\prime} \mathrm{N}\right)$ in 2008. The field study area was on the main experimental land of ZAFU and surrounded by other experimental greenhouses and the entire area was flat. The field is characterized by a humid subtropical climate with an average rainfall of $135 \mathrm{~cm} \mathrm{yr}^{-1}(104-166 \mathrm{~cm})$ and an average temperature of $17.58^{\circ} \mathrm{C}\left(-6^{\circ}-40^{\circ} \mathrm{C}\right)(\mathrm{Gu}$ et al. 2009). The soil is the typical red soil of Zhejiang Province and the properties of the top $10 \mathrm{~cm}$ of the soil were measured using samples collected in April 2008 before the selected tree seedlings were planted as shown in Table 1.

S. superba, which is distributed over large areas of southern China, is used for firewood, heliophilous and the dominant species in the subtropical forest ecosystems of the Yangtze Delta region (Lin and Zhou 2009). Mo et al. (2008) pointed out that the $S$. superba grows in relatively nutrient-poor soils. With an increasing concentration about the $\mathrm{N}$ deposition effects on subtropical forest trees in Yangtze River Delta, it is necessary to examine the $\mathrm{N}$ addition effects on seedling growth and physiological research on S. superba. 
Table 1. Mineral soil properties ( 0 - $10 \mathrm{~cm}$ depth) of the study field (Means with S.E. in parentheses, $n=3$ for samples).

\begin{tabular}{|c|c|c|c|c|c|c|}
\hline & Total N g.kg-1 & Available N mg kg $^{-1}$ & Available $\mathrm{K} \mathrm{mg} \mathrm{kg}^{-1}$ & Available P mg $\cdot k^{-1}$ & Organic C $\mathbf{~ g} \cdot \mathbf{k g}^{-1}$ & pH \\
\hline Soil & $7.30 \pm 0.41$ & $57.3 \pm 0.5$ & $71.0 \pm 3.0$ & $2.91 \pm 0.05$ & $12.4 \pm 1.0$ & $5.18 \pm 0.03$ \\
\hline
\end{tabular}

\subsection{Experimental Design}

The experiment was conducted on a $6 \times 24 \mathrm{~m}$ field and arranged with a completely randomized design with four $\mathrm{N}$ treatments after consulting research by Mo et al. (2008). There were five replicates for each treatment. Twenty plots of dimensions $1.6 \times 1.6 \mathrm{~m}$ were established and each plot was surrounded by a $0.5 \mathrm{~m}$ wide buffer strip. In April, 2008, 2-year-old seedlings of $S$. superba were transplanted into the experimental field. Nine seedlings of $S$. superba were separately planted in each plot with a spacing of $0.5 \times 0.5 \mathrm{~m}$.

Precipitation nitrogen deposition was $7.12 \mathrm{~kg} \mathrm{~N} \mathrm{ha}^{-1}$ year $^{-1}$ in $1995,32.01 \mathrm{~kg} \mathrm{~N}^{-1}$ year $^{-1}$ in 2002 (Deng et al. 2007) and $30.9 \mathrm{~kg} \mathrm{~N} \mathrm{ha}^{-1}$ year $^{-1}$ in 2005 (Xie et al. 2008) in the Hangzhou region. Four $\mathrm{N}$ addition treatments were established: $\mathrm{CK}$ (Control, $0 \mathrm{~g} \mathrm{~N} \mathrm{~m}^{-2}$ year $\left.^{-1}\right), \mathrm{LN}\left(6 \mathrm{~g} \mathrm{~N} \mathrm{~m}^{-2}\right.$ year $\left.^{-1}\right)$, MN $\left(10 \mathrm{~g} \mathrm{~N} \mathrm{~m}^{-2}\right.$ year $\left.^{-1}\right)$, and $\mathrm{HN}\left(24 \mathrm{~g} \mathrm{~N} \mathrm{~m}^{-2}\right.$ year $\left.{ }^{-1}\right)$. All plots and treatments were laid out randomly. $\mathrm{NH}_{4} \mathrm{NO}_{3}$ nitrogen fertilizer was applied in equal amounts once a week from April, 2009. The fertilizers were dissolved in $17.035 \mathrm{~L}$ of water (the annual amount of water was equivalent to $8.7 \mathrm{~mm}$ precipitation) and sprayed on five plots using a backpack sprayer. The Control (CK) plots were sprayed with the same water volume without added $\mathrm{N}$.

\subsection{Plant Growth, Net Photosynthetic Rate, Chlorophyll Concentration and Spectral Reflectance Measurements}

Height and stem base diameters of 5 randomly selected seedlings from each plot were measured in May, August and November during 2009 - 2010.

The net photosynthetic rate $\left(\mathrm{Pn}, \mu \mathrm{mol} \mathrm{CO} \mathrm{Cm}^{-2} \mathrm{~s}^{-2}\right)$ was measured with a Li-6400 portable photosynthesis system (Li-Cor Inc., USA) in May, August and November during 2009 - 2010. Every $1 \mathrm{~h}$, from 6:00 to 17:00, five leaves from seedlings per plot from each treatment were chosen for measurement.

Plant leaf chlorophyll content measurements were obtained using a portable chlorophyll meter (SPAD-502, Minolta, Japan) from each plot of the in situ $\mathrm{N}$ treatments with the same times for spectral measurements. For measurement accuracy 10 readings were taken from every leaf sample and then averaged into one SPAD value.

Hyperspectral data were obtained using a FieldSpec FR spectroradiometer manufactured by Analytical Spectral Devices Inc. (ASD). The spectral resolution of this instrument is $3 \mathrm{~nm}$ for the $350-1000 \mathrm{~nm}$ range and $10 \mathrm{~nm}$ for the $1000-2500 \mathrm{~nm}$ range. Reflectance measurements were obtained six times during three seasons (spring, summer, and autumn) between 2009 and 2010. At each level of $\mathrm{N}$ treatment for every plot, 30 samples of $S$. superba seedlings leaves were selected to obtain the spectral reflectance in situ. Spectral reflectance was calculated as the ratio of measured radiance to radiance from a white standard (Analytical Spectral Devices Inc., ASD) taken under the same sky conditions and immediately preceding the plant radiance measurements.

\subsection{Hyperspectral Indices}

The red edge variables were derived from the first derivative of the reflectance. The first derivative is commonly used to enhance absorption features that might be masked by interfering background absorptions and canopy background effects (Mutanga and Skidmore 2007). The first derivative spectra were calculated from each reflectance spectrum. A first difference transformation of the reflectance spectrum calculates the slope values from the reflectance and can be derived from the following equation (Mutanga and Skidmore 2007):

$$
F D S_{\lambda(i)}=\left[R_{\lambda(j+1)}-R_{\lambda(j)}\right] / \Delta_{\lambda}
$$

Where $F D S$ is the first derivative reflectance at a wavelength $i$ that is a midpoint between wavebands $j$ and $j+1$. $\mathbf{R}_{\lambda(j)}$ is the reflectance at the $j$ waveband, $\mathbf{R}_{\lambda(j+1)}$ is the reflectance at the $j+1$ waveband and $\Delta_{\lambda}$ is the difference in wavelengths between $j$ and $j+1$.

The variables derived from the first derivative reflectance contained the red edge position and amplitude. Amplitude is the first derivatives value at the red edge peaks composed of two or more features.

Some leaf reflectance ratios measured within narrow wavebands $(2 \mathrm{~nm})$ were also evaluated as indicators of plant stress and the most strongly indicated plant stress was reflectance at $695 \mathrm{~nm}$ divided by reflectance at $420 \mathrm{~nm}\left(\mathrm{R}_{695 / 420}\right)$ and $760 \mathrm{~nm}\left(\mathrm{R}_{695 / 760}\right)$ (Carter 1994).

\subsection{Data Analyses}

One-way analysis of variance (ANOVA) was used to test the differences for $S$. superba seedlings on seedling height, stem base diameter, net photosynthetic rate and chlorophyll concentration, respectively. A multiple comparison 
with Duncan's test was made after ANOVA for the differences in plant growth parameters of $S$. superba. Relationship between chlorophyll content values and hyperspectral indices were examined with linear regression analysis. All analyses were conducted using SPSS 13.0 for windows.

\section{RESULTS}

\subsection{Seedling Growth, Net Photosynthetic Rate and Chlorophyll Concentration}

Compared to CK plots, values for both seedling height and stem base diameter to $\mathrm{N}$ addition generally showed a positive low rate effect from $\mathrm{N}$ addition and no significant high rate effect from $\mathrm{N}$ addition for S. superba (Figs. 1a, b). The highest values were observed in the MN plots and lowest values appeared in the $\mathrm{CK}$ and $\mathrm{HN}$ plots. An increase in both seedling height and stem base diameter was found in the LN plots for S. superba. However, the increasing trend was lower than MN plots. These patterns above became more pronounced with time, indicating the cumulative effect of $\mathrm{N}$ addition. Repeated-measure ANOVA showed significant statistical significant difference in both seedling height and stem base diameter for $S$. superba over the entire study period ( $p<0.05$, Fig. 1 ).

Similar to the seedling height and stem base diameter response, the net photosynthetic rate $(\mathrm{Pn})$ increased from lower rate $\mathrm{N}$ addition and decreased from higher rate $\mathrm{N}$ addition for $S$. superba, with the highest values observed in the MN plots and the lowest Pn was also found in CK plots (Fig. 1c).

The SPAD reading responses to $\mathrm{N}$ treatment are shown in Fig. 2. It indicates that the chlorophyll in S. superba seedlings in a given sampling, according to SPAD measurements, were different depending on the different levels of $\mathrm{N}$ treatment. SPAD readings indicated that the seedlings in the MN application rate had higher chlorophyll content than their counterparts in the $\mathrm{CK}, \mathrm{LN}$ and $\mathrm{HN}$ application rate plots. A clearly similar chlorophyll content pattern in the
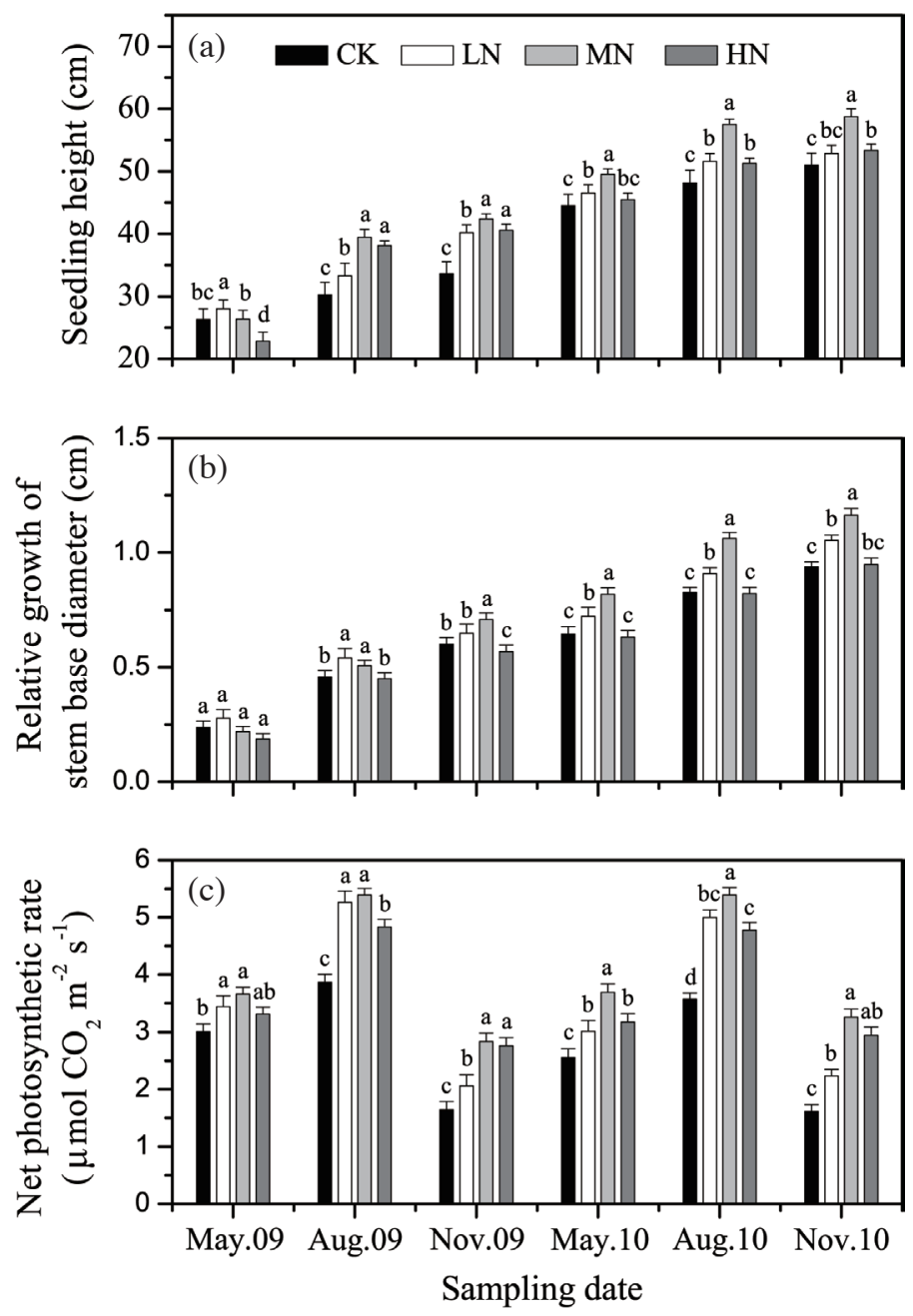

Fig. 1. Nitrogen addition effects on seedling stem base diameter (a), height (b) and net photosynthetic rate (c) of $S$. superba in the experimental field of ZAFU. Different letters above the columns indicates significant difference among treatments $(p<0.05)$. Data were measured after 12 months of nitrogen addition. 


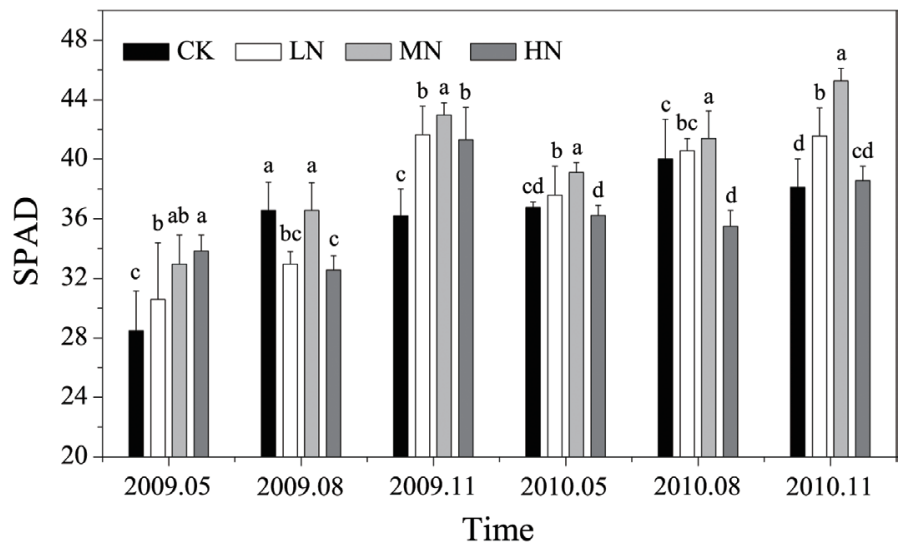

Fig. 2. Comparisons of SPAD chlorophyll content for $S$. superba in four simulated $\mathrm{N}$ stress treatments during the six experiments. Different letters above each column indicates significant differences among treatments $(p<0.05$, repeated-measure ANOVA).

LN plot appeared after the MN group. In the first year of $\mathrm{N}$ addition (2009), the HN plot showed a higher chlorophyll content throughout the year compared with the control plot. However, this pattern changed in the next year (2010) and thereafter, the HN plot had the lowest chlorophyll content compared with the other applications. Our study also shows that the chlorophyll content in $S$. superba seedlings increased in the short-term with $\mathrm{N}$ addition and decreased in the longterm with $\mathrm{HN}$ addition (Fig. 2). In our study the chlorophyll content in $S$. superba plants in all treatments increased during the two year growth cycles, especially the $\mathrm{LN}$ and $\mathrm{MN}$ treatments. However, regarding the different seasons, the chlorophyll content in S. superba plants decreased at the end of their growth cycle (autumn) compared to the beginning of their growth cycle (spring and summer).

\subsection{Plant Spectral and Hyperspectral Indices}

The reflectance spectra of individual leaves were significantly different among the four $\mathrm{N}$ treatments through most of the wavelengths measured (Fig. 3) in different seasons during the two years. The most pronounced change in leaf reflectance spectra due to $\mathrm{N}$ addition was in the visible bands at the chlorophyll absorbance peak near the red wavelengths. Reflectance decreased in the red with increasing $\mathrm{N}$ application in the spring and autumn over the two years. This trend was inversed in summer. Compared to different $\mathrm{N}$ application plots, the reflectance at the visible wavelengths was lower in LN (except autumn of 2009) and MN plots compared to $\mathrm{CK}$ in two years. The reflectance at the visible bands was lower in the HN plots than the CK plots in the early stages of the spring and summer of 2009. However, it was higher in the spring and summer of 2010. The HN application reflectance at the visible bands was lower than CK in the autumn of both years. Note that the reflectance in the red for the $\mathrm{CK}$ and LN plots present a similar trend throughout the autumn season in response to the induced lower chloro- phyll content caused by less $\mathrm{N}$ availability in the leaves of plants within the no $\mathrm{N}$ or lower $\mathrm{N}$ application rates. Compared to the $\mathrm{CK}$ plots, the significant differences in the green and red spectrum of $\mathrm{LN}$ - CK and MN - CK were indicated the variations in chlorophyll content, which are associated with nutrient levels caused by different levels of available nitrate. However, it also generally reduces the chlorophyll content with overabundant nitrate applied and shows unobvious differences in reflectance in the visible spectrum at the chlorophyll absorbed between CK and HN plots.

The red edge peak showed a shift to longer wavelengths with two or more peaks appearing in the first derivative curve throughout the $S$. superba plants growth cycle (Fig. 4). Plants in MN and HN treatment, whose chlorophyll content was increasing at the initial stages of the growth cycle (2009), showed a maximal shift to longer wavelengths (shift from 705 to $713 \mathrm{~nm}$ relative to the control) and a large increase in red edge amplitude (Fig. 4 and Table 2). At the later stages of the growth cycle (2010), plants in LN and MN treatment showed a maximal shift to longer wavelengths (shift from 705 to $713 \mathrm{~nm}$ relative to the control) (Fig. 4 and Table 2).

At the beginning of the growth cycle a red edge peak presents at around $700 \mathrm{~nm}$. This peak became the main peak in the CK treatments over the two years while the peak moved to around $720 \mathrm{~nm}$ and became dominant in the $\mathrm{LN}$ and $\mathrm{MN}$ treatments in the 2010 growth cycle (Fig. 4 and Table 2).

The red-edge peaks in the derivative spectra were composed of a peak maximum at around $700 \mathrm{~nm}$ and a smaller peak or shoulder between 715 and $725 \mathrm{~nm}$ (Fig. 4). These features were used to detect differences between the control and $\mathrm{N}$-stressed plants. A ratio of the magnitudes of the derivative at 720 and $700 \mathrm{~nm}\left(\mathrm{R}_{700} / \mathrm{R}_{720}\right.$, Table 2) was calculated to determine if changes in these wavelengths could be used to monitor the $\mathrm{N}$ addition effect on $S$. superba.

It was observed that in the early stage (2009) of $\mathrm{N}$ treatment the ratio of $\mathrm{R}_{700} / \mathrm{R}_{720}$ decreased along with the 
increasing supply of $\mathrm{N}$, while in the later stage (2010) the ratio of $R_{700} / R_{720}$ was lower in the $L N$ and $M N$ plots than in the control and HN plants.

Carter reported that the ratios of $\mathrm{R}_{695} / \mathrm{R}_{420}$ and $\mathrm{R}_{695} / \mathrm{R}_{760}$ computed within the visible to near-infrared spectrum were affected most strongly by plant stress (Carter 1994). There were higher values of these two ratios in the stressed plants compared with the value in non-stressed plants for various stress agents that did not include $\mathrm{N}$ stress.

These two ratios $\left(\mathrm{R}_{695} / \mathrm{R}_{420}\right.$ and $\left.\mathrm{R}_{695} / \mathrm{R}_{760}\right)$ had a similar characteristic in that the lower value appeared in the MN and HN treatments in the early stage (2009) of the experiment and in the LN and MN plots in the later stage (2010). This indicated that $S$. superba seedling growth was promoted under the MN and HN plots at the early stage (2009) of $\mathrm{N}$ addition treatment and in the $\mathrm{LN}$ and $\mathrm{MN}$ plots at the later stage (2010).

Absorption by chlorophylls a and $\mathrm{b}$ was relatively weak at $695 \mathrm{~nm}$. Thus as the leaf chlorophyll content began to decrease with the occurrence of stress, leaf reflectance increased first and then most significantly at or near this wavelength. At $420 \mathrm{~nm}$, absorption by chlorophylls or other pigments was strong and chlorophylls were lost before reflectance would increase significantly at or near this wavelength. Thus, the ratio of $R_{695} / R_{420}$ may ultimately prove to be an indicator of chlorophyll content in S. superba to N addition treatments. The near-infrared $(760 \mathrm{~nm})$ reflectance indicated low sensitivity to stress. This result indicated that reflectance in the near-infrared $(760-800 \mathrm{~nm})$ wavelengths could be divided into reflectance at $695 \mathrm{~nm}$ to produce a stress-sensitive ratio (Carter 1994). Our result indicated that the ratios containing $R_{695} / R_{420}$ and $R_{695} / R_{760}$, such as the stress indices, could be used to reveal the $\mathrm{N}$ stress response in S. superba in the Yangtze River Delta.

\subsection{Relationships Between Leaf Reflectance and Leaf Chlorophyll}

SPAD readings, which reflected the leaf chlorophyll content in $S$. superba seedlings by extension, were found

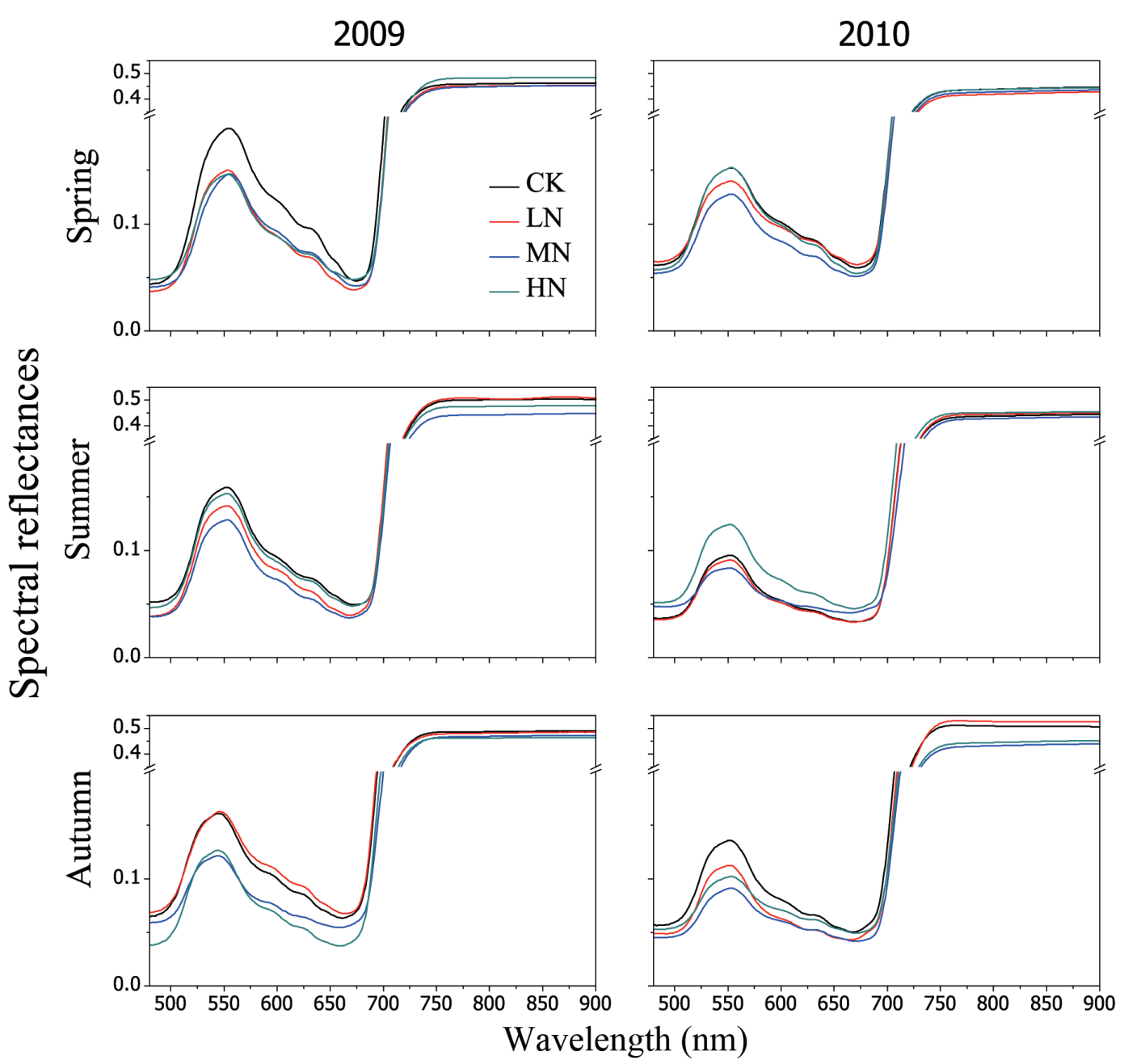

Fig. 3. Average reflectance spectrum of S. superba under the four experimental treatments (CK, LN, MN and HN) in different seasons over two years. 


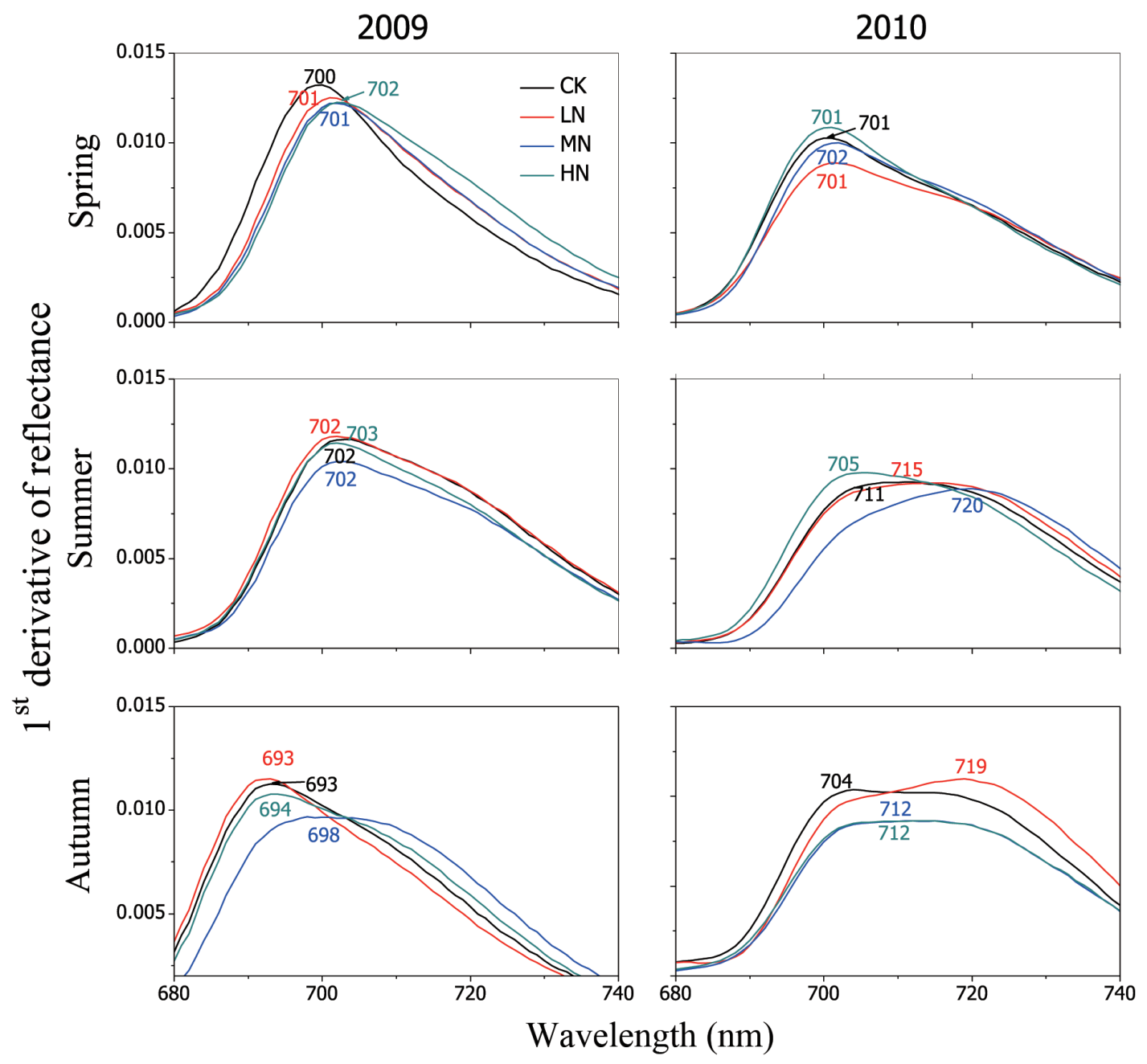

Fig. 4. The first derivative spectrum curves of red-edge reflectance for $S$. superba plants under four different treatments and along the growth cycle, respectively. The numbers were the red edge peak wavelength (RE) derived in IG model for S. superba plants.

Table 2. Four indices indicating $S$. superba stress under the simulated $\mathrm{N}$ additional treatment in six experiments, respectively.

\begin{tabular}{cccccc}
\hline \multirow{2}{*}{ Ratios } & Times & \multicolumn{4}{c}{ N Additional levels } \\
\cline { 3 - 6 } & & CK & LN & MN & HN \\
\hline \multirow{2}{*}{ RE $(\mathrm{nm})$} & 2009.05 & 701.68 & 704.29 & $\mathbf{7 0 4 . 9 7}$ & $\mathbf{7 0 6 . 3 5}$ \\
& 2009.08 & 698.14 & 699.69 & $\mathbf{7 0 7 . 8 8}$ & $\mathbf{7 0 6 . 9 2}$ \\
& 2009.11 & 697.23 & 695.29 & $\mathbf{7 0 1 . 3 3}$ & $\mathbf{6 9 8 . 9 3}$ \\
& 2010.05 & 705.64 & $\mathbf{7 0 7 . 0 5}$ & $\mathbf{7 0 6 . 8 6}$ & 705.32 \\
& 2010.08 & 711.36 & $\mathbf{7 1 1 . 6 3}$ & $\mathbf{7 1 3 . 7 2}$ & 709.45 \\
& 2010.11 & 709.00 & $\mathbf{7 1 0 . 8 8}$ & $\mathbf{7 1 1 . 2 4}$ & 710.77 \\
\hline $\mathrm{R}_{700} / \mathrm{R}_{720}$ & 2009.05 & 2.28 & 1.83 & $\mathbf{1 . 7 7}$ & $\mathbf{1 . 5 0}$ \\
& 2009.08 & $\mathbf{1 . 2 8}$ & 1.33 & $\mathbf{1 . 3 1}$ & 1.39 \\
& 2009.11 & 1.92 & 2.10 & $\mathbf{1 . 4 3}$ & $\mathbf{1 . 7 1}$ \\
& 2010.05 & 1.57 & $\mathbf{1 . 3 6}$ & $\mathbf{1 . 4 5}$ & 1.68 \\
& 2010.08 & 0.89 & $\mathbf{0 . 8 3}$ & $\mathbf{0 . 6 2}$ & 1.05 \\
& 2010.11 & 0.99 & $\mathbf{0 . 8 0}$ & $\mathbf{0 . 8 9}$ & 0.91 \\
\hline
\end{tabular}


Table 2. (Continued)

\begin{tabular}{cccccc}
\hline \multirow{2}{*}{ Ratios } & Times & \multicolumn{4}{l}{ N Additional levels } \\
\cline { 3 - 6 } & & CK & LN & MN & HN \\
\hline $\mathrm{R}_{695} / \mathrm{R}_{420}$ & 2009.05 & 3.23 & 2.84 & $\mathbf{2 . 5 0}$ & $\mathbf{2 . 1 3}$ \\
& 2009.08 & 4.27 & 5.10 & $\mathbf{1 . 9 2}$ & $\mathbf{2 . 2 1}$ \\
& 2009.11 & $\mathbf{3 . 2 4}$ & 3.26 & $\mathbf{2 . 5 8}$ & 4.48 \\
& 2010.05 & 1.85 & $\mathbf{1 . 6 8}$ & $\mathbf{1 . 7 6}$ & 1.90 \\
& 2010.08 & 1.54 & 1.61 & $\mathbf{1 . 1 6}$ & $\mathbf{1 . 4 6}$ \\
& 2010.11 & 1.52 & $\mathbf{1 . 4 5}$ & $\mathbf{1 . 4 5}$ & 1.46 \\
\hline $\mathrm{R}_{695} / \mathrm{R}_{760}$ & 2009.05 & 0.27 & $\mathbf{0 . 2 1}$ & $\mathbf{0 . 2 1}$ & $\mathbf{0 . 2 0}$ \\
& 2009.08 & 0.37 & 0.38 & $\mathbf{0 . 1 9}$ & $\mathbf{0 . 2 0}$ \\
& 2009.11 & 0.43 & 0.46 & $\mathbf{0 . 3 3}$ & $\mathbf{0 . 3 7}$ \\
& 2010.05 & 0.25 & $\mathbf{0 . 2 4}$ & $\mathbf{0 . 2 2}$ & 0.25 \\
& 2010.08 & 0.14 & $\mathbf{0 . 1 3}$ & $\mathbf{0 . 1 3}$ & 0.17 \\
& 2010.11 & 0.18 & $\mathbf{0 . 1 4}$ & $\mathbf{0 . 1 5}$ & 0.17 \\
\hline
\end{tabular}

to be at best negatively correlated with green reflectance at 559 and $717 \mathrm{~nm}$ which indicated the red edge of S. super$b a$ leaf reflectance (Fig. 5a). The positive correlation then appeared at blue $(450 \mathrm{~nm})$ and red $(680 \mathrm{~nm})$ reflectance. Similarly, some researchers also found that reflectance at 545 - 555 nm (Jacquemoud and Baret 1990; Daughtry et al. 2000; Zhao et al. 2003), 620 - $680 \mathrm{~nm}$ (Reddy et al. 2001) and $712 \mathrm{~nm}$ (Carter and Spiering 2002; Zhao et al. 2003) were good predictors of chlorophyll in several crops. We found a significant correlation between chlorophyll SPAD readings and reflectance at $559 \mathrm{~nm}$ across all $\mathrm{N}$ application rate areas as shown in Fig. 5b $(\mathrm{R}=-0.77)$. These findings would make the remote leaf chlorophyll content estimation of $S$. superba trees at the field scale by aircraft possible, although multiple years of data are necessary to strengthen these relationships.

In order to determine the relationship between leaf spectral reflectance ratios and leaf chlorophyll concentration, leaf reflectance ratio data (RE, $\mathrm{R}_{700} / \mathrm{R}_{720}, \mathrm{R}_{695} / \mathrm{R}_{420}$, and $\mathrm{R}_{695} / \mathrm{R}_{760}$ ) in Table 2 and Fig. 4, as well as the chlorophyll SPAD readings in Fig. 2, were averaged across replicate leaves and then pooled across the $\mathrm{N}$ treatments and sampling dates $(n=24)$. Simple correlation analysis and linear regression indicated that although the leaf reflectance indices were negatively (positively for RE index) and significantly correlated with leaf chlorophyll $(p \leq 0.05)$, the correlations were strongest in the four indices shown in Fig. $6(\mathrm{R}=0.74-0.86)$. The results indicated strong linear relationships between the reflectance indices and chlorophyll content measured in individual $S$. superba leaves.

\section{DISCUSSION}

The chlorophyll content has the seasonal variation in the plant growth cycle in the subtropical region. In the early growth period the chlorophyll content is lower in leaves because of lower temperatures and less precipitation in spring.
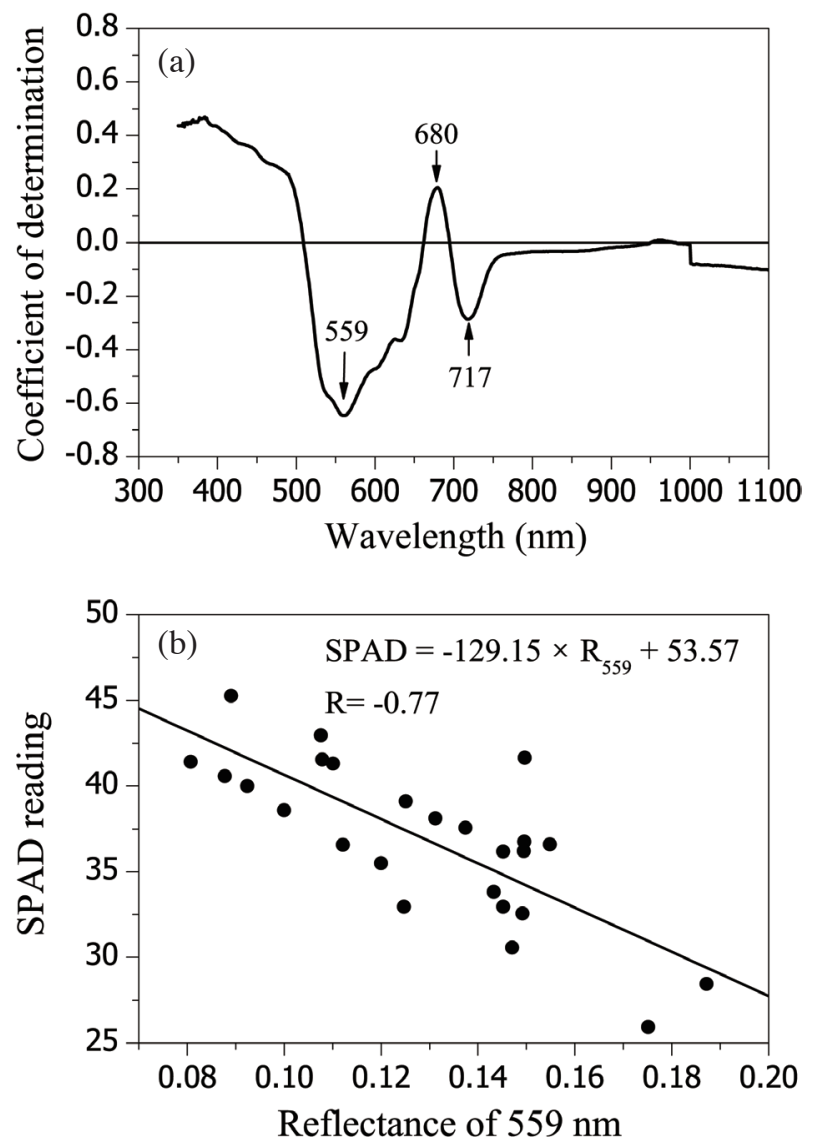

Fig. 5. (a) Correlation by wavelength between SPAD reading and foliage reflectance; (b) the relationship between SPAD reading and foliage reflectance at $559 \mathrm{~nm}$ for four nitrogen application treatments. 

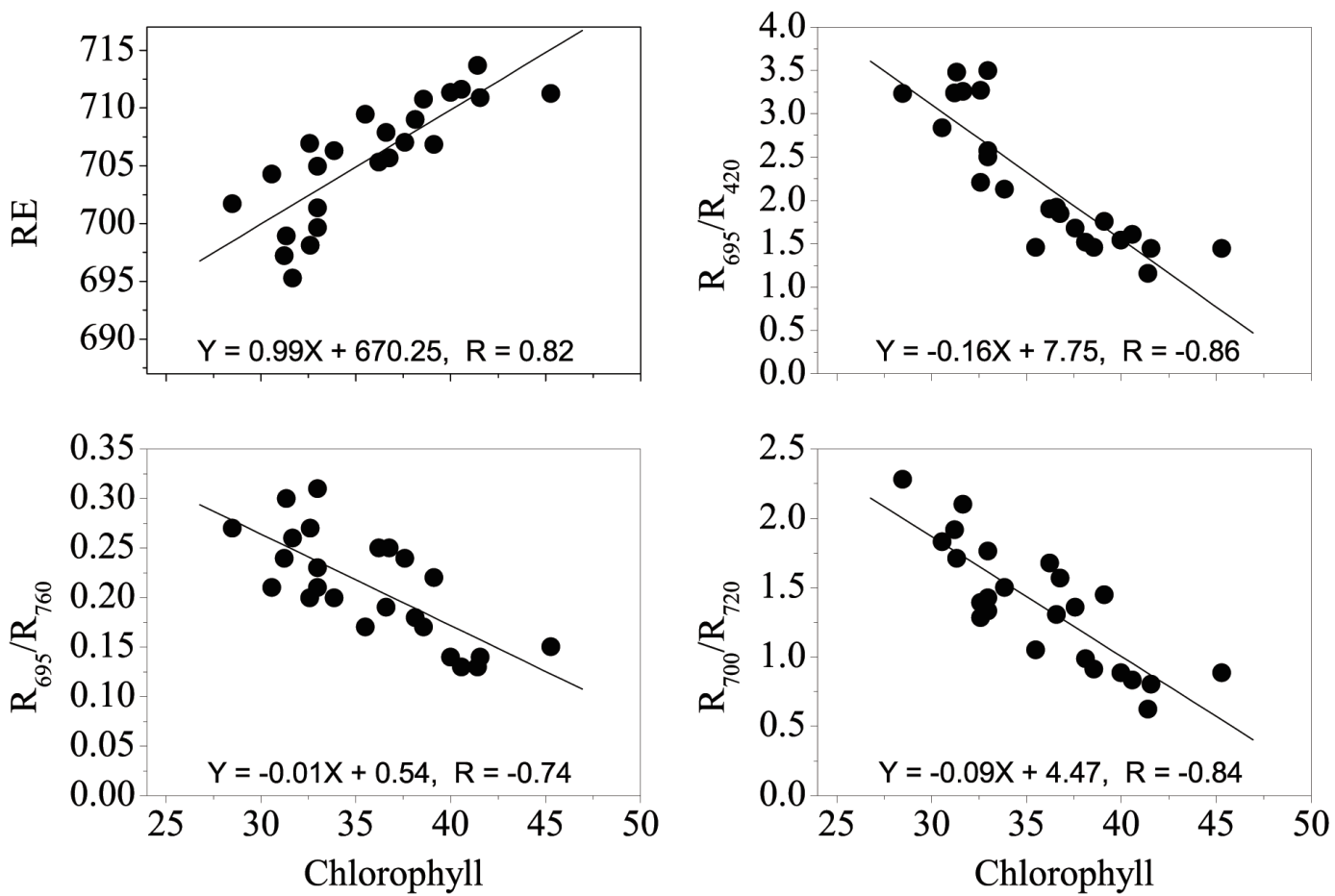

Fig. 6. Linear regression of S. superba leaf pigment with specific reflectance ratios that can indicate N stress in Table 2 and Fig. 4 with SPAD chlorophyll content in Fig. 5. Data were combined among the four treatments and six sampling dates $(n=24)$.

Chlorophyll content reaches the maximum value at in the vigorous growth stage with temperature and precipitation suitable for S. superba plants growth in summer. Leaf senescence and growth slows in autumn, with the chlorophyll content decreasing to a lower value because of lower temperature and less precipitation. In general, the chlorophyll content of evergreen leaves in seasonal order of magnitude as the summer $>$ autumn $>$ spring. However, in this study, the two-year observed impact of enhanced $\mathrm{N}$ supply was a delay in leaf senescence during the autumn stages. So the chlorophyll content of $S$. superba plants had showed the seasonal order of magnitude as the autumn $>$ summer $>$ spring.

The chlorophyll content as an indicator of plant stress could reflect the nutritional status of plants because of the relationship between the chlorophyll concentration and the nitrogen content in foliage (Richardson et al. 2002; Song et al. 2008). Spaner et al. (2005) also reported that the SPAD measurement readings were indeed influenced by plant nitrogen status at a critical stage. This was correlated with protein content and yield in crop plants (Spaner et al. 2005). Our results also indicated that the long-term observed impact of additional MN enhanced the chlorophyll content in S. superba seedlings during the two year experimental stages, while the short-term impact of additional HN promoted the chlorophyll content during the early stages but was limited during the later stages.

Hansen and Schjoerring (2003) indicated that nitrogen supply caused an average lower reflectance in the visible spectral range (438 - $690 \mathrm{~nm}$ ), while the reflectance was higher in the near infrared spectral range $(750-883 \mathrm{~nm})$. This characteristic was also found in the early stages of our experiment as lower reflectance in the visible wavelengths appeared in the HN plots in the spring of 2009, while the reflectance was higher in the near infrared region. The same characteristics were shown in the LN plots in the summer of 2009 and autumn of 2010. This characteristic disappeared at the other stages of the experiment. With the study of field corn, Strachan et al. (2002) indicated that the growth of crops is a function of the availability of $\mathrm{N}$ and environmental stresses and there can be a complex interaction among these stresses. Our result also could be interpreted by the different controlled experimental conditions. The experiment of simulated $\mathrm{N}$ addition treatment in S. superba was conducted in a natural environment and was affected by other environmental stresses such as water availability and radiation stress. Coupled with the seasonal factor, there could be a complex interaction between $\mathrm{N}$ stress and other environmental stresses (Strachan et al. 2002).

Several researches have shown that the peak revealed by red edge reflectance derivative analysis is actually composed of two or more features (Horler et al. 1983; Lamb et al. 2002). There are two peaks in the derivative spectra; the first at around $700(690-710) \mathrm{nm}$ attributed to the chlorophyll content in the plant leaves and the second at around $725(720-730) \mathrm{nm}$ attributed to cellular scattering in the leaf (Horler et al. 1983). They found that the shorter wavelength 
feature indicates environmental stress for plants whereas the longer wavelength feature indicates better environment for plants (Smith et al. 2004). The peak at around $705 \mathrm{~nm}$ is dominant if the leaves have low chlorophyll content while the peak at around $725 \mathrm{~nm}$ is dominant if the leaves have higher chlorophyll levels (Lamb et al. 2002). In our study this characteristic was first seen in the autumn of 2009 for the MN treatment and then appeared in the summer and autumn of 2010 for all treatments.

The chlorophyll content and four hyperspectral indices (RE, $R_{700} / R_{720}, R_{695} / R_{420}$, and $R_{695} / R_{760}$ ) showed a positive response to the lower rates of $\mathrm{N}$ addition with the most positive response seen at the $\mathrm{MN}$ rate but responded negatively to the higher $\mathrm{N}$ addition rate $(\mathrm{HN})$. The positive response mentioned above suggests that $\mathrm{N}$ is likely a limiting factor for S. superba seedling growth in the Yangtze River Delta soil and is similar to the results found in the seedlings experiment at the DHSBR, which lies in the middle region of Guangdong province in southern China (Mo et al. 2008). Our findings are consistent with the results found for the biomass production and net photosynthetic rate of $S$. superba, in which they increased with increasing $\mathrm{N}$ addition rate from the control to $\mathrm{N} 10\left(10 \mathrm{~g} \mathrm{~N} \mathrm{~m}^{-2}\right.$ year $\left.^{-1}\right)$ and then decreased with increasing $\mathrm{N}$ addition rate from $\mathrm{N} 15\left(15 \mathrm{~g} \mathrm{~N} \mathrm{~m}^{-2}\right.$ year $\left.{ }^{-1}\right)$ to N30 (30 g N m${ }^{-2}$ year $^{-1}$ ) (Mo et al. 2008). Similar results were also reported for a temperate tree species (C.japonica) measured for biomass production and net photosynthetic rate for seedlings by Nakaji et al. $(2001,2002)$. Thus, the $\mathrm{N}$ deposition effect on $S$. superba seedling growth could be detected using vegetation growth parameters, photosynthesis and chlorophyll concentration.

There may be a growth threshold in the $\mathrm{N}$ deposition effect on $S$. superba seedlings according to our study. The $\mathrm{N}$ deposition threshold effect was also observed in a study on subtropical tree species $S$. superba and $C$. concinna under $\mathrm{N}$ addition (Mo et al. 2008). They found that the highest seedling growth parameter values were observed in N10 (10 $\mathrm{g} \mathrm{N} \mathrm{m}^{-2}$ year $\left.^{-1}\right)$ plots for $S$. superba. In our study, the highest increase in chlorophyll content and positive response reflected by hyperspectral indices were also observed in MN $\left(10 \mathrm{~g} \mathrm{~N} \mathrm{~m}^{-2}\right.$ year $\left.^{-1}\right)$ plot for $S$. superba. This is very consistent with the research of Mo et al. 2008.

The main reason the threshold occurred may be the soil $\mathrm{N}$ availability. It has been reported that when the amount of available $\mathrm{N}$ in forest soil does not exceed the requirement for seedling growth, an increase in the atmospheric $\mathrm{N}$ input usually stimulates tree growth. However, when the $\mathrm{N}$ input to forests is in excess of plant requirements it is harmful to tree growth because of nutrient leaching and soil acidification (Mo et al. 2008). They also suggested that $S$. superb demands less $\mathrm{N}$ for seedling growth. In our study the seedling growth of S. superb was less sensitive to lower $\mathrm{N}$ deposition rate (LN) and more pronounced to the higher $\mathrm{N}$ addition rate $(\mathrm{MN}$ and $\mathrm{HN})$ in these experiments.
Our study indicated that the $\mathrm{N}$ deposition effect for $S$. superba seedlings was detected rapidly and easily using nondestructive leaf spectral reflectance measurements at narrow wavebands. However, further investigations need to be carried out to determine if hyperspectral ratios could be used on airborne platforms with moderate spectral resolution for monitoring the $\mathrm{N}$ deposition effects for the natural $S$. superba plant. On the other hand, there is also a fundamental implication for forest dynamics and forest management in the Yangtze River Delta region. S. superba grows in relatively nutrient-poor soils and is a dominant tree species in both pine-broadleaf mixed and mature forests. With the increasing $\mathrm{N}$ deposition to forests in this region the population of $S$. superba may be threatened along with the accumulation of $\mathrm{N}$ in the soil.

\section{CONCLUSIONS}

We used plant growth parameters and indices derived from ground based hyperspectral reflectance data to demonstrate the temporal patterns in S. superba growth when exposed to nitrogen (different application rates). In the absence of other limiting factors, growth is a function of the availability of N. Our results indicated that High-N deposition may not enhance plant growth, net photosynthetic rate and chlorophyll concentration in S. superba, while LN and MN treatments could enhance plant growth in a given experimental period.

In remote sensing this complex dynamic, several hyperspectral reflectance signatures and indices were required to assess the evolution of $S$. superba seedling ecophysiology. Accurate identification of the relationship between chlorophyll concentration and hyperspectral indices was obtained using simple correlation analysis and linear regression in the seasons. This technique offers a means for estimating the chlorophyll concentration using the reflectance signatures information provided by hyperspectral data sets. When taken at an appropriate scale and timing, hyperspectral reflectance can provide valuable information to identify plant nitrogen nutrition stressed regions in order to implement forest management.

Acknowledgments This study was supported by the NSF China Major Program (61190114 and 41171324), the Funds for Ph.D. Education (20110091110028), the National Key Project of Basic Research (2010CB428503), the Research Innovation Program for College Graduates of Jiangsu Province (CXZZ110035) and the program B for Outstanding PhD candidate of Nanjing University (201301B011).

\section{REFERENCES}

Bates, N. R. and A. J. Peters, 2007: The contribution of atmospheric acid deposition to ocean acidification in the 
subtropical North Atlantic Ocean. Mar. Chem., 107, 547-558, doi: 10.1016/j.marchem.2007.08.002. [Link]

Carter, G. A., 1993: Responses of leaf spectral reflectance to plant stress. Am. J. Bot., 80, 239-243, doi: 10.2307/ 2445346. [Link]

Carter, G. A., 1994: Ratios of leaf reflectances in narrow wavebands as indicators of plant stress. Int. J. Remote Sens., 15, 697-703, doi: 10.1080/01431169408954109. [Link]

Carter, G. A. and B. A. Spiering, 2002: Optical properties of intact leaves for estimating chlorophyll concentration. J. Environ. Qual., 31, 1424-1432, doi: 10.2134/ jeq2002.1424. [Link]

Cheng, M., H. Jiang, Z. Guo, X. Zhang, and X. Lu, 2013: Estimating $\mathrm{NO}_{2}$ dry deposition using satellite data in eastern China. Int. J. Remote Sens., 34, 2548-2565, doi: 10.1080/01431161.2012.747019. [Link]

Daughtry, C. S. T., C. L. Walthall, M. S. Kim, E. Brown de Colstoun, and J. E. McMurtrey III, 2000: Estimating corn leaf chlorophyll concentration from leaf and canopy reflectance. Remote Sens. Environ., 74, 229-239, doi: 10.1016/S0034-4257(00)00113-9. [Link]

Deng, M., Y. Xie, Z. Xiong, G. Xing, and X. Yan, 2007: Nitrogen budgets of the Yangtze Delta Region and their effect on the environment. Acta Sci. Circumst., 27, 1709-1716.

Fang, S. and Y. Mu, 2007: $\mathrm{NO}_{\mathrm{x}}$ fluxes from three kinds of agricultural lands in the Yangtze Delta, China. Atmos. Environ., 41, 4766-4772, doi: 10.1016/j. atmosenv .2007.02.015. [Link]

Galloway, J. N. and E. B. Cowling, 2002: Reactive nitrogen and the world: 200 years of change. AMBIO: J. Hum. Environ., 31, 64-71, doi: 10.1579/0044-7447-31.2.64. [Link]

Galloway, J. N., H. Levy II, and P. S. Kasibhatla, 1994: Year 2020: Consequences of population growth and development on deposition of oxidized nitrogen. Ambio, 23, 120-123.

Gu, B., J. Chang, Y. Ge, H. Ge, C. Yuan, C. Peng, and H. Jiang, 2009: Anthropogenic modification of the nitrogen cycling within the Greater Hangzhou Area system, China. Ecol. Appl., 19, 974-988, doi: 10.1890/080027.1. [Link]

Hansen, P. M. and J. K. Schjoerring, 2003: Reflectance measurement of canopy biomass and nitrogen status in wheat crops using normalized difference vegetation indices and partial least squares regression. Remote Sens. Environ., 86, 542-553, doi: 10.1016/S0034-4257(03)00131-7. [Link]

Hoque, E. and P. J. S. Hutzler, 1992: Spectral blue-shift of red edge minitors damage class of beech trees. Remote Sens. Environ., 39, 81-84, doi: 10.1016/0034-4257(92)90142-7. [Link]

Horler, D. N. H., M. Dockray, and J. Barber, 1983: The red edge of plant leaf reflectance. Int. J. Remote Sens., 4, 273-288, doi: 10.1080/01431168308948546. [Link]

Jacquemoud, S. and F. Baret, 1990: PROSPECT: A model of leaf optical properties spectra. Remote Sens. Environ., 34, 75-91, doi: 10.1016/0034-4257(90)90100-Z. [Link]

Lamb, D. W., M. Steyn-Ross, P. Schaare, M. M. Hanna, W. Silvester, and A. Steyn-Ross, 2002: Estimating leaf nitrogen concentration in ryegrass (Lolium spp.) pasture using the chlorophyll red-edge: Theoretical modelling and experimental observations. Int. J. Remote Sens., 23, 3619-3648, doi: 10.1080/01431160110114529. [Link]

Lin, L. and Z. C. Zhou, 2009: Effects of soil moisture condition and phosphorus supply on the seedlings growth and phosphorus efficiency of Schima superba provenances. Chin. J. Appl. Eco., 20, 2617-2623. (in Chinese)

Lu, X., J. Mo, F. S. Gilliam, G. Zhou, and Y. Fang, 2010: Effects of experimental nitrogen additions on plant diversity in an old-growth tropical forest. Global Change Biol., 16, 2688-2700, doi: 10.1111/j.1365-2486.2010. 02174.x. [Link]

Lu, X., J. Mo, F. S. Gilliam, G. Yu, W. Zhang, Y. Fang, and J. Huang, 2011: Effects of experimental nitrogen additions on plant diversity in tropical forests of contrasting disturbance regimes in southern China. Environ. Pollut., 159, 2228-2235, doi: 10.1016/j.envpol.2010.10.037. [Link]

Magill, A. H., J. D. Aber, W. S. Currie, K. J. Nadelhoffer, M. E. Martin, W. H. McDowell, J. M. Melillo, and P. Steudler, 2004: Ecosystem response to 15 years of chronic nitrogen additions at the Harvard Forest LTER, Massachusetts, USA. For. Ecol. Manage., 196, 7-28, doi: 10.1016/j.foreco.2004.03.033. [Link]

Mo, J., S. Brown, J. Xue, Y. Fang, and Z. Li, 2006: Response of litter decomposition to simulated $\mathrm{N}$ deposition in disturbed, rehabilitated and mature forests in subtropical China. Plant Soil, 282: 135-151, doi: 10.1007/s11104-005-5446-7. [Link]

Mo, J., W. Zhang, W. Zhu, Y. Fang, D. Li, and P. Zhao, 2007: Response of soil respiration to simulated $\mathrm{N}$ deposition in a disturbed and a rehabilitated tropical forest in southern China. Plant Soil, 296, 125-135, doi: 10.1007/s11104-007-9303-8. [Link]

Mo, J., D. Li, and P. Gundersen, 2008: Seedling growth response of two tropical tree species to nitrogen deposition in southern China. Eur. J. Forest Res., 127, 275283, doi: 10.1007/s10342-008-0203-0. [Link]

Moffat, A. S., 1998: Global nitrogen overload problem grows critical. Science, 279, 988-989, doi: 10.1126/ science.279.5353.988. [Link]

Mutanga, O. and A. K. Skidmore, 2007: Red edge shift and biochemical content in grass canopies. ISPRS: J. Photogramm.,62,34-42,doi: 10.1016/j.isprsjprs.2007.02.001. [Link] 
Nakaji, T., M. Fukami, Y. Dokiya, and T. Izuta, 2001: Effects of high nitrogen load on growth, photosynthesis and nutrient status of Cryptomeria japonica and Pinus densiflora seedlings. Trees, 15, 453-461.

Nakaji, T., S. Takenaga, M. Kuroha, and T. Izuta, 2002: Photosynthetic response of Pinus densiflora seedlings to high nitrogen load. Environ. Sci., 9, 269-282.

Nixon, S. W., 1995: Coastal marine eutrophication: A definition, social causes, and future concerns. Ophelia, 41, 199-219.

Pattey, E., I. B. Strachan, J. B. Boisvert, R. L. Desjardins, and N. B. McLaughlin, 2001: Detecting effects of nitrogen rate and weather on corn growth using micrometeorological and hyperspectral reflectance measurements. Agric. For. Meteorol., 108, 85-99, doi: 10.1016/ S0168-1923(01)00232-5. [Link]

Reddy, G. S., C. L. N. Rao, L. Venkataratnam, and P. V. K. Rao, 2001: Influence of plant pigments on spectral reflectance of maize, groundnut and soybean grown in semi-arid environments. Int . J. Remote Sens., 22, 33733380, doi: 10.1080/01431160152609218. [Link]

Richardson, A. D., S. P. Duigan, and G. P. Berlyn, 2002: An evaluation of noninvasive methods to estimate foliar chlorophyll content. New Phytol., 153, 185-194, doi: 10.1046/j.0028-646X.2001.00289.x. [Link]

Richter, A., J. P. Burrows, H. Nüß, C. Granier, and U. Niemeier, 2005: Increase in tropospheric nitrogen dioxide over China observed from space. Nature, 437, 129132, doi: 10.1038/nature04092. [Link]

Smith, K. L., M. D. Steven, and J. J. Colls, 2004: Use of hyperspectral derivative ratios in the red-edge region to identify plant stress responses to gas leaks. Remote Sens. Environ., 92, 207-217, doi: 10.1016/j. rse.2004.06.002. [Link]

Song, X., H. Jiang, S. Yu, and G. Zhou, 2008: Detection of acid rain stress effect on plant using hyperspectral data in Three Gorges region, China. Chinese Geogr. Sci., 18, 249-254, doi: 10.1007/s11769-008-0249-4. [Link]
Spaner, D., A. G. Todd, A. Navabi, D. B. McKenzie, and L. A. Goonewardene, 2005: Can leaf chlorophyll measures at differing growth stages be used as an indicator of winter wheat and spring barley nitrogen requirements in eastern Canada? J. Agron. Crop Sci., 191, 393-399, doi: 10.1111/j.1439-037X.2005.00175.x. [Link]

Strachan, I. B., E. Pattey, and J. B. Boisvert, 2002: Impact of nitrogen and environmental conditions on corn as detected by hyperspectral reflectance. Remote Sens. Environ., 80, 213-224, doi: 10.1016/S0034-4257(01)00299-1. [Link]

van Breemen, N., 2002: Nitrogen cycle: Natural organic tendency. Nature, 415, 381-382, doi: 10.1038/415381a. [Link]

Vitousek, P. M. and R. W. Howarth, 1991: Nitrogen limitation on land and in the sea: How can it occur? Biogeochemistry, 13, 87-115, doi: 10.1007/BF00002772. [Link]

Vitousek, P. M., J. D. Aber, R. W. Howarth, G. E. Likens, P. A. Matson, D. W. Schindler, W. H. Schlesinger, and D. G. Tilman, 1997: Human alteration of the global nitrogen cycle: Sources and consequences. Ecol. Appl., 7, 737-750, doi: 10.1890/1051-0761(1997)007[0737:HAOTGN]2.0.CO;2. [Link]

Xie, Y. X., S. L. Zhang, X. Zhao, Z. Q. Xiong, and G. X. Xing, 2008: Seasonal variation patterns of $\mathrm{NH}_{4}{ }^{+}-\mathrm{N} /$ $\mathrm{NO}_{3}{ }^{-}-\mathrm{N}$ ratio and delta $15 \mathrm{NH}_{4}^{+}$value in rainwater in Yangtze River Delta. J. Appl. Ecol., 19, 2035-2041.

Zhao, D., K. R. Reddy, V. G. Kakani, J. J. Read, and G. A. Carter, 2003: Corn (Zea mays L.) growth, leaf pigment concentration, photosynthesis and leaf hyperspectral reflectance properties as affected by nitrogen supply. Plant Soil, 257, 205-217, doi: 10.1023/ A:1026233732507. [Link]

Zheng, X., C. Fu, X. Xu, X. Yan, Y. Huang, S. Han, F. $\mathrm{Hu}$, and G. Chen, 2002: The Asian nitrogen cycle case study. AMBIO: J. Hum. Environ., 31, 79-87, doi: 10.1579/0044-7447-31.2.79. [Link] 